\title{
НОВЫЕ ДАННЫЕ О ЛИШАЙНИКАХ РОДА UMBILICARIA HOFFМ. С ОСТРОВОВ ПАРАМУШИР И САХАЛИН
}

\author{
Еюккин А. К. ${ }^{1}$, Давыдов Е. А. $^{2}$ \\ ${ }^{\prime}$ ФГБУН Институт морской геологии и геофизики ДВО РАН, г. Южно-Сахалинск \\ ${ }^{2}$ ФГБОУ ВО Алтайский государственный университет, г. Барнаул \\ E-mail: ezhkin@yandex.ru, eadavydov@yandex.ru
}

\begin{abstract}
Приводятся новые данные о лишайниках из рода Umbilicaria Hoffm. с о-вов Парамушир и Сахалин. Для о. Парамушир приведено 6 видов лишайников, 4 из них - Umbilicaria cylindrica, $U$. deusta, $U$. hyperborea и $U$. torrefacta - являются новыми для территории. Для о. Сахалин приведен 1 новый вид - U. muhlenbergii, найденный на древних останцах Тонино-Анивского полуострова. Среди представленных видов три - Umbilicaria deusta, U. muhlenbergii и $U$. hyperborea впервые приведены для Сахалинской области. Для всех видов даны краткие описания, места сборов и иллюстрации.
\end{abstract}

Ключевые слова: Северные Курилы, Дальний Восток России, вулканическая активность, скальная растительность.

DOI: $10.34078 / 1814-0998-2021-1-75-80$

\section{ВВЕДЕНИЕ}

Остров Парамушир находится на самом севере Большой Курильской гряды и является вторым

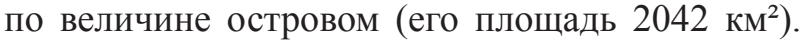
Длина острова составляет более 100 км, средняя ширина - около 19-22 км. С северо-запада он омывается Охотским морем, с юго-востока Тихим океаном. Со стороны моря остров сильно изрезан заливами, высок и обрывист, береговая полоса узкая. Со стороны океана берег более пологий и сложный по рельефу, с низменными участками побережья, бухтами, крутыми мысами и множеством скалистых рифов. Остров представляет собой цепочку вулканов, плотно слившихся своими подошвами. Всего на острове находится 40 голоценовых вулканов, 5 из них активные. Действующий вулкан Чикурачки (1816 м) является самой высокой точкой острова. Благодаря особенностям горного рельефа и большому количеству осадков, территория острова покрыта густой речной сетью, которая представлена в основном малыми реками длиной не более 10 км и многочисленными ручьями, имеющими горный характер: с быстрыми течениями, водопадами, порогами (Котенко, Котенко, 2013). По А. И. Земцовой (1968), остров входит в климатический район «Северные Курилы», где наи-

(с) Ежкин А. К., Давыдов Е. А., 2021 более холодная и менее пасмурная зима, более холодное лето, чем на других Курильских островах. На острове крайне жесткий ветровой режим, частые туманы и короткий вегетационный период. Флора острова по своему видовому составу близка к камчатской и обогащена арктоальпийскими элементами (Баркалов, 2009). Основным типом растительности здесь являются заросли кедрового стланика, рододендрона, верещатников и кустарниковой камчатской ольхи, занимающие нижние части склонов гор. Верхние части склонов занимают каменные осыпи с лишайниками. Равнинные участки сильно заболочены или заняты тундровой растительностью (Злобин и др., 2004).

Остров Сахалин расположен вблизи восточного берега Азиатского материка и является самым крупным островом в России. С запада и югозапада он омывается водами теплого Японского моря, с севера и востока - холодным водами Охотского моря. Остров гористый, горы низкие и средневысотные, не более 1000-1100 м н. у. м. (Толмачев, 1955). Территория острова характеризуется влажным муссонным климатом, значительным количеством осадков, теплыми южными ветрами летом и холодными северо-западными ветрами зимой (Земцова, 1968). Около $2 / 3$ территории острова занимают леса. На севере преобладают леса и редколесья из лиственницы Гмели- 
на. В центральной и южной частях острова господствует темнохвойная тайга из ели аянской и пихты сахалинской, с подъемом в горы пихтовоеловые леса сменяются лесами из каменной березы и зарослями кедрового стланика.

Род Umbilicaria Hoffm. объединяет около 100 видов лишайников, обитающих, за редким исключением, на кислом каменистом субстрате и распространенных в горах и высоких широтах на всех континентах (Davydov et al., 2017). В России известны 43 вида рода Umbilicaria (Давыдов, 2017; Давыдов и др., 2019), в горных и арктических флорах род входит в ведущие по числу видов и играет важную роль в заселении каменистых субстратов, особенно на верхней границе леса и в высокогорных поясах. Для островов Сахалинской области ранее было приведено 6 видов рода Umbilicaria, для п-ова Камчатка - 17 видов (Davydov et al., 2011). Для о. Парамушир до написания настоящей статьи были известны 2 вида рода - Umbilicaria proboscidea (L.) Schrad. (Sato, 1936) и U. vellea (L.) Ach. (Davydov et al., 2020).

\section{МАТЕРИАЛ И МЕТОДЫ}

Сбор образцов лишайников рода Umbilicaria был осуществлен на о. Парамушир в сентябре и октябре 2017 г. маршрутным методом. Были исследованы каменистые субстраты на склонах вулкана Крашенинникова (рис. 1) и в районе м. Озерный (рис. 2).
Обработку и определение материалов проводились в лаборатории береговых геосистем Института морской геологии и геофизики ДВО РАН Идентификация лишайников выполнена в соответствии с традиционными лихенологическими методиками (Окснер, 1974 ; Андреев и др., 2014). Названия таксонов даны согласно базе данных Index Fungorum, электронного ресурса - CABI Bioscience Databases http://www.indexfungorum.org.

\section{РЕЗУЛЬТАТЫ}

В настоящей работе приводится 6 видов для о. Парамушир, 4 из них являются новыми для острова (рис. 3). Дополнительно в статье приводится один новый вид для о. Сахалин - $U$. muhlenbergii, найденный на древних останцах Тонино-Анивского полуострова (рис. 4).

Umbilicaria cylindrica (L.) Delise

Широко распространенный в Арктике и гоpax Северного полушария вид, характеризующийся светло- или темно-серым листоватым слоевищем 2-5 (10) см в диаметре, с разветвленными черными ресничками. В Сахалинской области U. cylindrica был отмечен для о. Итуруп (Домбровская, 1987). Для о. Парамушир приводится впервые.

Исследованные образцы: о. Парамушир, м. Озерный, Черные Озера, прибрежный луг, N 50³5'24.2”, Е 15609'41”, 57 м н. У. м., на скалах. 03.10.2017. Собрал: Ежкин А. К., определил: Давыдов Е. А. 1295, 1296 (SAK).

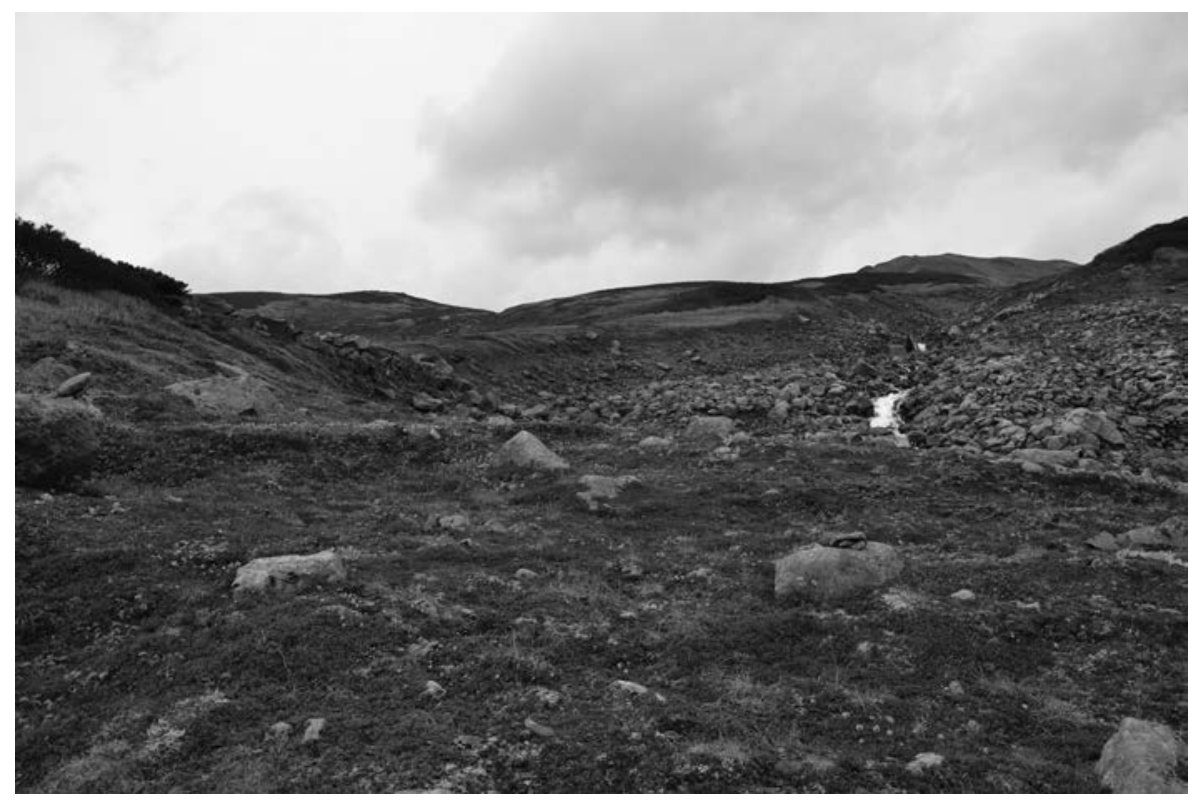

Puc. 1. Горная тундра с камнями и валунами на склоне вулкана Крашенинникова, о. Парамушир

Fig. 1. Mountain tundra with stones and boulders on the slope of Krasheninnikov Volcano, Paramushir Island 

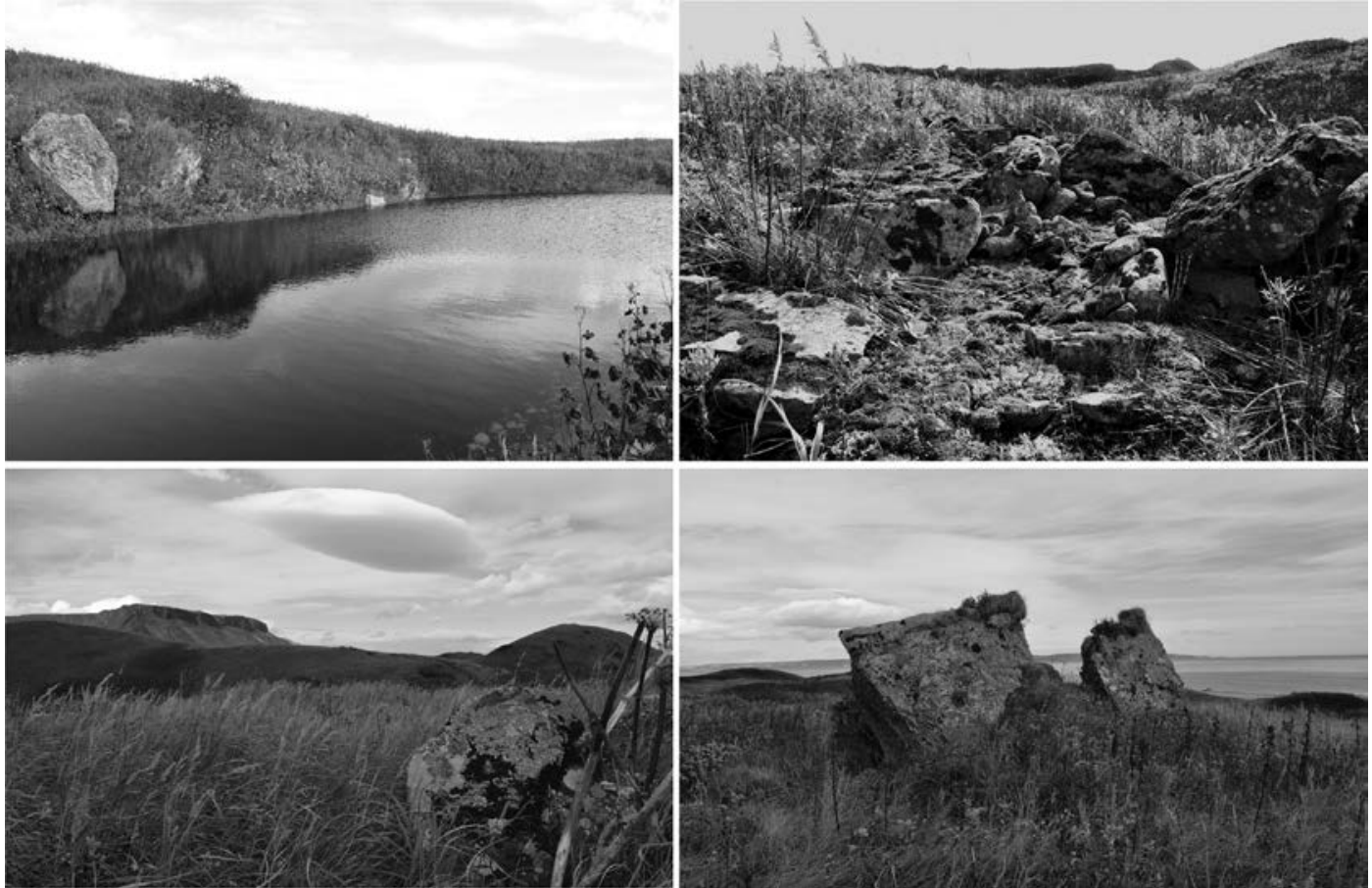

Pис. 2. Каменистые субстраты в районе м. Озерный, о. Парамушир

Fig. 2. Rock substrates in the vicinity of Cape Ozerny, Paramushir Island
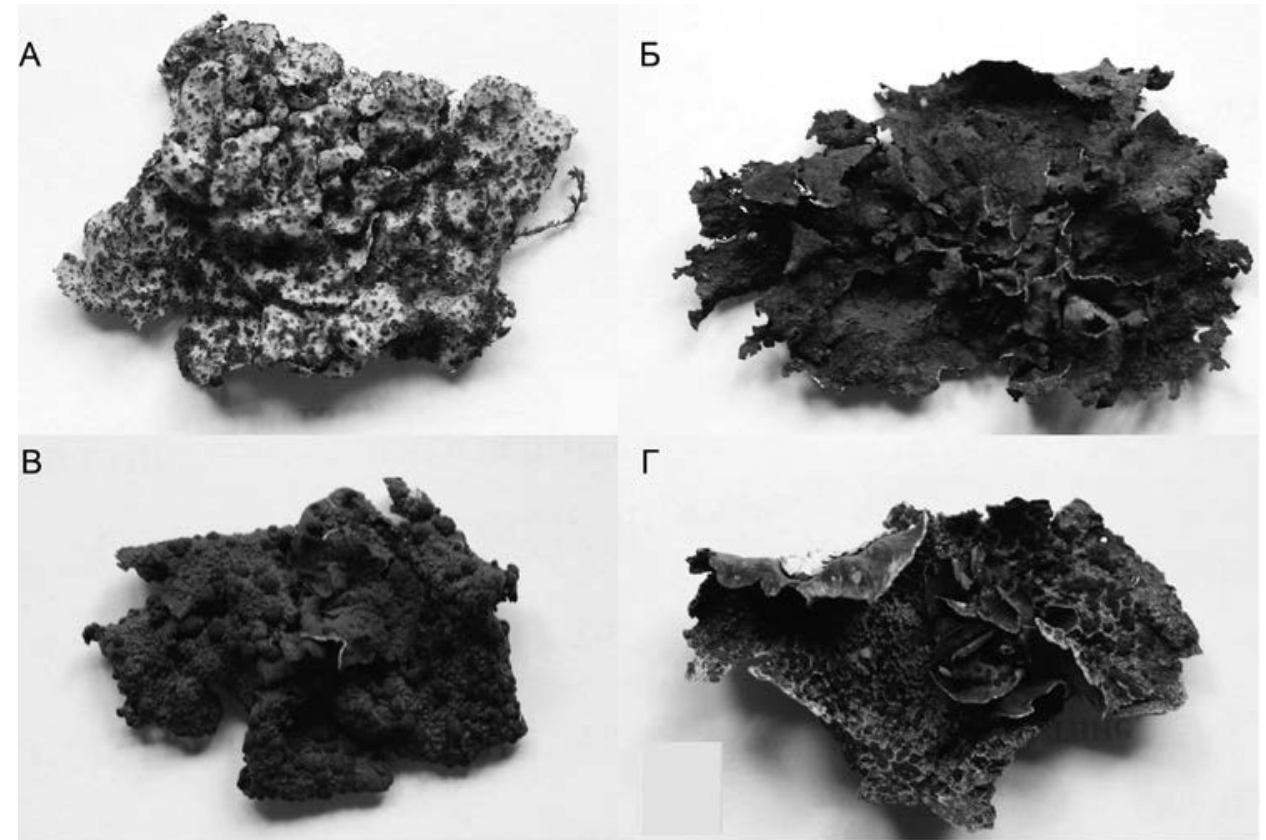

$\Gamma$
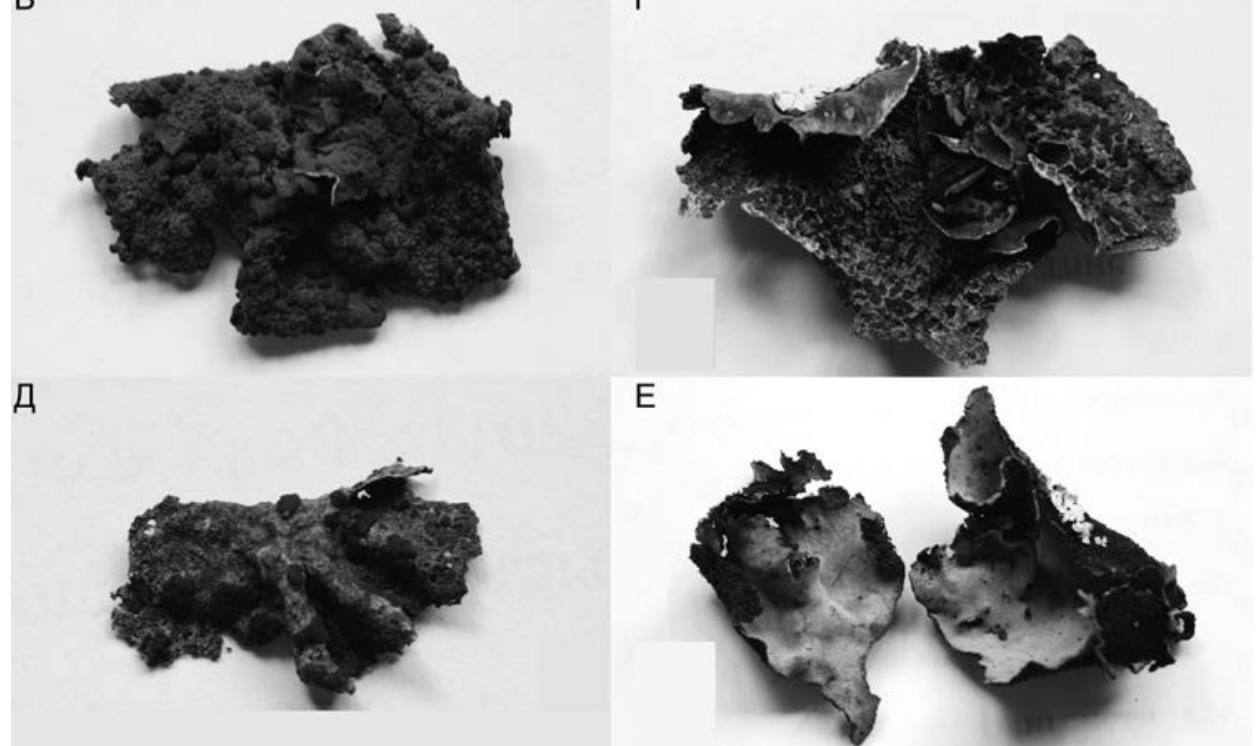

Puc. 3. Лишайники рода Umbilicaria с о. Парамушир: А - Umbilicaria cylindrica, Б - U. deusta, В - U. hyperborea, $\Gamma-U$. proboscidea, Д-U. torrefacta, E-U. vellea

Fig. 3. Lichens of the Umbilicaria genus from Paramushir Island: A - Umbilicaria cylindrica, Б $-U$. deusta, $\mathrm{B}-U$. hyperborea, $\Gamma-U$. proboscidea, Д-U. torrefacta, E-U. vellea 


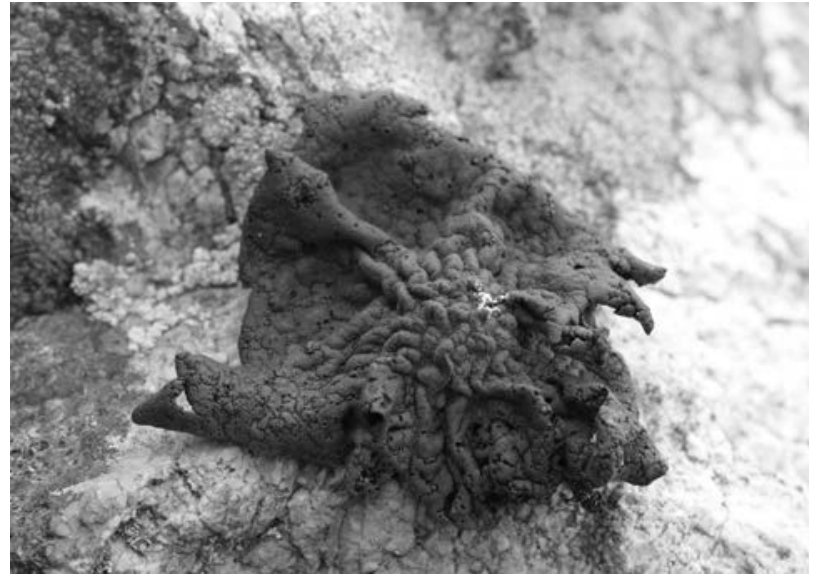

Puc. 4. Umbilicaria muhlenbergii на скалах ТониноАнивского полуострова, о. Сахалин

Fig. 4. Umbilicaria muhlenbergii on the rocks of the Tonin-Aniva Peninsula, Sakhalin Island

Umbilicaria deusta (L.) Baumg.

Голарктический вид, обитающий на равнине, особенно в арктических широтах, и в горах в лесном поясе и нижней части высокогорного. Характеризуется черно-коричневым листоватым слоевищем 2-4 (8) см в диаметре, с загнутыми лопастями, цилиндрическими разветвленными или плоскими изидиями, а также отсутствием апотециев. $U$. deusta ранее был отмечен для юга Дальнего Востока - Приморский и Хабаровский края (Чабаненко, 2002). Для о. Парамушир и Сахалинской области приводится впервые.

Исследованные образцы: о. Парамушир, м. Озерный, Черные Озера, прибрежный луг, N 50³5'24.2”, Е 15609'41”, 57 м н. у. м., на старых лавовых потоках. 03.10.2017. Собрал: Ежкин А. К., определил: Давыдов Е. А. 1300 (SAK).

Umbilicaria muhlenbergii (Ach.) Tuck.

Голарктический вид, слоевище монофильное, темно-коричневатое или серовато-коричневатое, морщинисто-складчатое, до $10 \mathrm{~cm}$ в диаметре, с сидящими в складках апотециями. $U$. muhlenbergii ранее был отмечен для юга Дальнего Востока - Приморский и Хабаровский края (Чабаненко, 2002). Определения вида для п-ова Камчатка были признаны ошибочными (Davydov et al., 2011). Для о. Сахалин и Сахалинской области вид приводится впервые.

Исследованные образцы: о. Сахалин, окр. пос. Новиково, Тонино-Анивский полуостров, смешанный вторичный лес, $\mathrm{N} 46^{\circ} 22^{\prime} 43.8^{\prime \prime}$, Е $143^{\circ} 28^{\prime} 16.1^{\prime \prime}, 172$ м н. у. м., на старых лавовых потоках. 24.08.2016. Собрал: Ежкин А. К., определил: Давыдов Е. А. 1301 (SAK).

Umbilicaria hyperborea (Ach.) Hoffm.

Широко распространенный в обоих полушариях лишайник. Характеризуется довольно тон- ким, темно-коричневым слоевищем 2-5 (10) см в диаметре с морщинистыми лопастями. Вид, близкий к U. arctica (Ach.) Nyl., но последний имеет более толстое слоевище. U. hyperborea ранее был отмечен для юга Дальнего Востока Приморский край (Чабаненко, 2002). Для о. Парамушир и Сахалинской области приводится впервые.

Исследованные образцы: о. Парамушир, вулкан Крашенинникова, г. Наседкина, горная тундра, N 50³7'51.6”, Е 15601'31.4”, 652 м н. у. м., на скалах. 29.09.2017. Собрал: Ежкин А. К., определил: Давыдов Е. А. 1293 (SAK); там же, м. Озерный, Черные Озера, прибрежный луг, N 50³5'24.2”, Е 15609'41”, 57 м, на старых лавовых потоках. 03.10.2017. Собрал: Ежкин А. К., определил: Давыдов Е. А. 1294, 1298, 1303 (SAK).

Umbilicaria proboscidea (L.) Schrad.

Широко распространенный арктический вид. Слоевище местами продырявленное с зубчатоили разорванно-надрезанными лопастями, с одиночными черными ресничками по краю, с многочисленными апотециями. Для ДВ России отмечен для п-ова Камчатка (Davydov et al., 2011). Для Парамушира приводился японскими специалистами под названием Gyrophora proboscidea (L.) Ach., под которым был также отмечен для о. Симушир (Sato, 1936).

Исследованные образцы: о. Парамушир, вулкан Крашенинникова, г. Наседкина, горная тундра, N 50³7'28.5", Е 15602'09.4", 492 м, на скалах. 30.09.2017. Собрал: Ежкин А. К., определил: Давыдов Е. А. 1299 (SAK); там же, м. Озерный, Черные Озера, прибрежный луг, N 50³5'24.2”, Е $156^{\circ} 09^{\prime} 40.9^{\prime \prime}, 57$ м н. у. м., на старых лавовых потоках. 03.10.2017. Собрал: Ежкин А. К., определил: Давыдов Е. А. 1297 (SAK).

Umbilicaria torrefacta (Lightf.) Schrad.

Голарктический вид, характеризуется монофильным, часто рассеченным слоевищем 2-4 (8) см в диаметре с перфорациями. В Сахалинской области отмечен для о. Сахалин и о. Атласова (Sato, 1936). Для о. Парамушир приводится впервые.

Исследованные образцы: о. Парамушир, м. Озерный, Черные Озера, прибрежный луг, N 50³5'24.2”, E 15609'41”, 57 м н. у. м., на старых лавовых потоках скалах. 03.10.2017. Собрал: Ежкин А. К., определил: Давыдов Е. А. 1304 (SAK).

Umbilicaria vellea (L.) Ach.

Выделяется среди других видов рода Umbilicaria наличием на нижней поверхности двух типов ризиноморф, образующих два яруca. Широко распространен в России (Davydov, 2017). Отмечен для юга Дальнего Востока - 
Приморский и Хабаровский края (Чабаненко, 2002). В Сахалинской области указан для о. Сахалин (Sato, 1936) и о. Парамушир (Davydov et al., 2020), где был собран на прибрежных скалах.

Исследованные образцы: о. Парамушир, м. Озерный, Черные Озера, прибрежный луг, N 50³5'24.2”, Е 15609'41”, 57 м н. у. м., на старых лавовых потоках. 03.10.2017. Собрал: Ежкин А. К., определил: Давыдов Е. А. 1302 (SAK).

\section{ОБСУЖДЕНИЕ}

По результатам исследований для о. Парамушир на настоящее время известно 6 видов лишайников из рода Umbilicaria. Из 6 видов, приведенных в настоящей статье, 4 являются новыми для острова - Umbilicaria cylindrica, U. deusta, U. hyperborea и U. torrefacta. Два из них - Umbilicaria deusta и U. hyperborea - впервые указываются для Сахалинской области. Все найденные на о. Парамушир лишайники ранее уже были отмечены для п-ова Камчатка, что указывает на некоторую общность видового разнообразия лишайников данной группы для этих территорий. На Камчатке указанные виды часто встречаются на лавовых потоках различного возраста, скальных выходах в пределах горной тундры и на прибрежных скалах (Davydov et al., 2011). Наличие общих видов лишайников из рода Umbilicaria на данных территориях объясняется не только близким географическим положением, но и довольно схожими ландшафтами вулканического происхождения. Стоит отметить довольно слабую изученность о. Парамушир на предмет распространения лишайников по причине удаленности самого острова и слабо развитой транспортной сети, что делает его одним из наиболее труднодоступных и малоизученных обитаемых островов Курильской гряды.

Работа выполнена при поддержке фонда РФФИ и Японского общества продвижения науки (грант № 1954-50010).

\section{ЛИТЕРАТУРА}

Андреев М. П., Ахти Т., Войщехович А. А., Гагарина Л. В., Герасимова Ю. В., Гимельбрант Д. Е., Давыдов Е. А., Конорева Л. А., Кузнеиова Е. С., Макрый T. В., Надеина О. В., Рандлане Т., Сааг А., Соколова И. В., Степанчикова И. С., Урбанавичюс Г. П. Флора лишайников России: Биология, экология, разнообразие, распространение и методы изучения лишайников. Москва ; Санкт-Петербург : Тов-во науч. изданий КМК, 2014. $392 \mathrm{c}$.

Баркалов В. Ю. Флора Курильских островов. Владивосток : Дальнаука, 2009. 468 с.

Давыдов Е. А. Семейство Umbilicariaceae // Флора лишайников России: Род Protoparmelia, семейства Coenogoniaceae, Gyalectaceae и Umbilicariaceae / отв. ред. М. П. Андреев, Д. Е. Гимельбрант. Москва; Санкт-Петербург : Тов-во науч. изданий КМК, 2017. C. $66-136$.

Давыдов Е. А., Урбанавичюс Г. П., Урбанавичене И. Н., Селиванов A. E. Umbilicaria freyi - новый для России вид лишайника и другие виды рода Umbilicaria из Приэльбрусья (Центральный Кавказ, КабардиноБалкария) // Turczaninowia. 2019. 22 (2). C. 94-109.

Домбровская A. B. Род Stereocaulon на Дальнем Востоке // Ботанические исследования за Полярным кругом. Апатиты, 1987. С. 47-65.

Земиова А. И. Климат Сахалина. Ленинград : Гидрометеоиздат, $1968.197 \mathrm{c}$.

Злобин Т. К., Фархутдинов И. П., Высоков М. С., Литенко Н. Л., Грабовский А. И., Еремин В. М., Воронов Г. А., Сафронов С. Н., Ковтунович П. Ю., Прядко А. Ф., Бернгард Р. П., Смирнов Н. А., Рукавец В. В., Шугаипов Н. А., Ковалева Г. В., Выголов Е. Ю. Курильские острова / отв. ред. Т. К. Злобин, М. С. Высоков. Сахалин : Кн. изд-во, 2004. 227 с.

Котенко Л. В., Котенко Т. А. Северные Курилы. Москва : Перо, 2013. 196 с.

Окснер А. Н. Определитель лишайников СССР. Вып. 2. Морфология, систематика и географическое распространение. Ленинград : Наука, 1974. 284 с.

Толмачев А. И. Геоботаническое районирование острова Сахалина. Москва; Ленинград : Изд-во АН CCCP, 1955. $121 \mathrm{c}$.

Чабаненко С. И. Конспект флоры лишайников юга российского Дальнего Востока. Владивосток : Дальнаука, 2002. 232 с.

Davydov E. A., Himelbrant D. E., Stepanchikova I. S. Contribution to the study of Umbilicariaceae (lichenized Ascomycota) in Russia. II. Kamchatka Peninsula // Herzogia. 2011. Vol. 24 (2). P. 229-241.

Davydov E. A., Peršoh D., Rambold G. Umbilicariaceae (lichenized Ascomycota) - trait evolution and a new generic concept // Taxon. 2017. Vol. 66 (6). P. 1282 1303. DOI: $10.12705 / 666.2$

Davydov E. A., Yakovchenko L. S., Galanina I., Paukov A., Frolov I., Ahti T. New records of lichens from the Russian Far East. III. Lichens of coastal habitats // Biodiversity. 2020 [In press].

Sato $M$. Notes on the lichen flora of Tisioma or the Kuriles // Shokubutusugaku Zasshi. 1936. Vol. 50. P. 610617. 


\title{
NEW RECORDS OF LICHENS OF THE GENUS UMBILICARIA HOFFM. FROM PARAMUSHIR AND SAKHALIN ISLANDS
}

\author{
A. K. Ezhkin', E. A. Davydov' \\ ${ }^{1}$ Institute of Marine Geology and Geophysics, FEB RAS, Yuzhno-Sakhalinsk \\ ${ }^{2}$ Altai State University, Barnaul
}

\begin{abstract}
The paper presents the new data on lichen of the genus Umbilicaria Hoffm. from Paramushir and Sakhalin islands. Six species from Paramushir Island are presented; four (Umbilicaria cylindrica, $U$. deusta, U. hyperborea, and U. torrefacta) are recorded in Paramushir for the first time. One more species, $U$. muhlenbergii, collected from ancient inselbergs on the Tonin-Aniva Peninsula, Sakhalin, was registered in the island for the first time. Three of the species discussed (Umbilicaria deusta, U. muhlenbergii, and U. hyperborea) are new for Sakhalin Oblast. Brief descriptions, localities and photos are presented for the reported species.
\end{abstract}

Keywords: Northern Kurils, Russia's Far East, volcanic activity, rock vegetation.

\section{REFERENCES}

Andreyev, M. P., Ahti, T., Voytsekhovich, A. A., Gagarina, L. V., Gerasimova, Yu. V., Gimelbrant, D. E., Davydov, E. A., Konoreva, L. A., Kusnetsova, E. S., Makriy, T. V., Nadeina, O. V., Randlane, T., Saag, A., Sokolova, I. V., Stepanchikova, I. S., Urbanavichus, G. P., 2014. Lichen Flora of Russia: Biology, Ecology, Diversity, Distribution, and Methods of Studying Lichens. Moscow - St. Petersburg, KMK Scientific Publishers Ltd. [In Russian].

Barkalov, V. Yu., 2009. Flora of Kurile Islands. Vladivostok, Dalnauka [In Russian].

Chabanenko, S. I., 2002. Synopsis of the Lichen Flora in the South of the Russian Far East. Vladivostok, Dalnauka [In Russian].

Davydov, E. A., 2017. Family Umbilicariaceae, The Lichen Flora of Russia: Genus Protoparmelia, Families Coenogoniaceae, Gyalectaceae and Umbilicariaceae. Eds. M. P. Andreyev, D. E. Himelbrant. Moscow St. Petersburg, KMK Scientific Press Ltd., 66-136 [In Russian].

Davydov, E. A., Himelbrant, D. E., Stepanchikova, I. S., 2011. Contribution to the Study of Umbilicariaceae (Lichenized Ascomycota) in Russia. II. Kamchatka Peninsula, Herzogia. 24 (2), 229-241.

Davydov, E. A., Peršoh, D., Rambold, G., 2017. Umbilicariaceae (Lichenized Ascomycota) - Trait Evolution and a New Generic Concept, Taxon. 66 (6), 1282-1303. DOI: $10.12705 / 666.2$

Davydov, E. A., Urbanavichus, G. P., Urbanavichene, I. N., Selivanov, A. E., 2019. Umbilicaria freyi-a New
Lichen Species for Russia and Other Noteworthy Records of Umbilicaria from the Elbrus Region (Central Caucasus, Kabardino-Balcaria), Turczaninowia. 22 (2), 94-109 [In Russian].

Davydov, E. A., Yakovchenko, L. S., Galanina, I., Paukov, A., Frolov, I., Ahti, T., 2020. New Records of Lichens from the Russian Far East. III. Lichens of Coastal Habitats, Biodiversity [In Press].

Dombrovskaya, A. V., 1987. Genus Stereocaulon on Far East, Botanical Researches in the Arctic Circle. 4765 [In Russian].

Kotenko, L. V., Kotenko, T. A., 2013. Northern Kurils. Moscow, Pero [In Russian].

Oxner, A. N., 1974. Handbook of Lichens of the USSR 2 (Morphology, Systematics and Geographical Distribution). Leningrad, Nauka [In Russian].

Sato, M., 1936. Notes on the Lichen Flora of Tisioma or the Kuriles, Shokubutusugaku Zasshi. 50, 610-617.

Tolmachev, A. I., 1955. Geobotanical Zoning of the Sakhalin Island. Moscow - Leningrad, AN SSSR [In Russian].

Zemtsova, A. I., 1968. Sakhalin Climate. Leningrad, Gidrometeoizdat [In Russian].

Zlobin, T. K., Vysokov, M. S., Farkhutdinov, I. P., Litenko, N. L., Grabovsky, A. I., Yeremin, V. M., Voronov, G. A., Safronov, S. N., Koftunovich, P. Yu., Pryadko, A. F., Berngard, R. P., Smirnov, N. A., Rukavets, V. V., Shugaipov, N. A., Kovalyova, G. V., Vygolov, E. Yu., 2004. Kuril Isles, Eds. T. K. Zlobin, M. S. Vysokov. Sakhalin [In Russian]. 